\title{
Introduction
}

\section{Towards Communities of Practice in Global Sustainability}

\author{
Carl A. Maida and Sam Beck
}

The community of practice is an organisational form that complements the current knowledge economy, which since the late twentieth century has accelerated with advances in information production and dissemination (Wenger 2000). Communities of practice ensure greater engagement for sustainability by the public as local and global actors. A paradigm that arose through the anthropological imagination, the community of practice is an organisational form that complements the current knowledge economy (Lave 1988). A community of practice provides a framework for understanding social learning in complex organisations, specifically the notion of knowing. For novices and experts alike, knowing within a community of practice is based upon socially defined competence, or the ability to act and to be viewed as a competent member. Belonging to a particular community is based upon engagement, imagination and alignment within a social learning system that supports and sustains members and the community itself. Communities of practice provide the framework for social learning, because members: share a sense of joint enterprise, indicative of the level of learning energy within the community; interact on the basis of mutuality, which points to the depth of social capital generated by mutual engagement; and share a repertoire of resources, indicating the degree of participants' self-awareness (Lave and Wenger 1991). This framework - of knowing, belonging, and social learning through more informal styles characteristic of a community of practice - provides members with the skills to engage meaningfully in knowledge production, exchange and transformation in complex organisations by creating new ways of 'being in the world'.

The Anthropocene characterises the current geological age when, since the industrial era, anthropogenic activities have become the major driver impacting on the Earth system - a time when the human domina- tion of nature is challenging our planetary boundaries, with consequent deforestation, pollution, climate change and species loss (Gibson and Venkateswar 2015). Complex environmental challenges, brought about by rapid development, the voracious exploitation of both natural and human environments for profit, and the growth of human populations, together with the current technological revolution that has changed both lifestyles and social norms, call for a new approach to learning that facilitates interdisciplinary action on behalf of sustainability. Integrative science and education has shifted the emphasis towards actively using what learners know to explore, negotiate, interpret and create through collaborative activities across disciplines (Bruffee 1999). As a potentially disruptive innovation, collaborative learning challenges researchers, students and the public to acknowledge their roles as participants engaged in producing knowledge that integrates and synthesises data from diverse fields into a whole-systems perspective providing resistance to normative and uncritical thinking, and developing alternative approaches to improving the quality of life.

Woven throughout this transition is the narrative of sustainability, understood as focusing on the physical development and institutional operating practices that meet the needs of present users without compromising the ability of future generations to meet their own needs, particularly with regard to use and waste of natural resources (Maida 2007). To this end, sustainable practices support ecological, human and economic health and vitality, with the presumption that resources are finite, and should be used with a view to long-term priorities and consequences. However, cultivating sustainability literacy and public engagement on its behalf requires diverse cultural perspectives, trans-generational timeframes and localto-global connectedness. The need to promote partic- 
ipatory approaches to sustainability literacy in the broader public is clear, however few communitybased approaches have been developed to date that integrate disciplines into a holistic perspective of Earth's natural and human systems.

Related to sustainability is the centuries-old controversy over how urbanisation and industrialisation affected the soil, water, air and other common resources. The debate pits those advocating for the local control of shared resources against proponents of centralised control of common holdings by state or corporate power - and this polarity has helped shape public policies and institutional arrangements. The 'tragedy of the commons' connotes, in part, the undesirable effects of population pressure on certain shared resources, especially commons, which originally refer to farming and grazing land, hunting and fishing areas, and places for the disposal of wastes to which all members of a society have access. These common pool resources were enclosed and restricted in the face of exploitation by individuals or groups attempting to maximise their own gain (Agrawal 2003). Collective and shared use of such resources was ended through economic manipulation and outright violence transferring the use of such resources into the hands of private ownership for profit. The literature on common pool resources and common property has focused on environmental degradation, resource depletion and the impoverishment of populations. Scholars of the commons have offered the re-invention of community-based conservation as a corrective (Ostrom 2008). Bio-regionalists envision a more equitable relationship between human and natural systems through reorganising society around common ecosystems or bioregions and upon sustainable principles. Some have called for a 'recovery of the commons' as a means of regaining local community through peoples' direct involvement in the web of the natural resources and rearranging the relationships that people have with each other by collaborating across differences (Reid and Taylor 2010). This would come about through a revitalised sense of citizenship based upon shared governance around food, water, soil and energy, and the release of human potentials. Such a place-focused politics would become viable if local communities were rebuilt upon ecological principles rather than upon political or economic centralisation and principles of privatisation. Defining and securing a satisfactory quality of life for localities impacted by restrictions resulting from state- and market-based commodification of the natural and cultural commons, including public space, is a key feature of the sustainability project.
Citizen science bridges researchers and the lay public, across diverse populations and subpopulations, on behalf of sustainability (Bäckstrand 2003). Regarding the production or transfer of critical knowledge, citizen science is decidedly personal and interpersonal in style, enacted from the bottom up, most often at the local level, and based on relationship building (Bonney et al. 2009). It involves science initiated and carried out by citizens not trained to be professional scientists. These independent citizen perspectives, tied to local geographies, tend to be more holistic and serve as a corrective to normative science, in that they liberate citizens from the norms and specialised practices of professional disciplines. Early lay efforts to monitor common-pool resources and common property were carried out by users who depended upon a given resource for long-term sustenance. These efforts focused on meeting local and regional challenges of environmental degradation and resource depletion that threatened watersheds, fisheries and pasturage, with a goal of building consensus among users of a particular resource, and limiting the control over such resources by non-local entities. Initial interest in citizen science concerned ecological and environmental health sciences, as average citizens became more aware of the impact of science and technology on their personal lives and their community's quality of life (Brossard et al. 2005). Bio-monitoring, or body-burden research, emerged in response to growing public demand for information about humans' exposure to chemicals in the environment (Morello-Forsch et al. 2005). Since then, community residents collaborating with environmental health scientists in universities and community-based organisations have monitored workplace toxins, air and water pollution, household lead, flame retardants in consumer products and environmental chemicals in breast milk (Morello-Forsch et al. 2009). On-the-ground data collection techniques, such as 'ground-truthing', seek residents' knowledge to identify pollution sources located in their communities and verify compiled data derived from standardised risk-screening of environmental indicators (Heaney et al. 2007).

Anthony Giddens' notion of life politics, or those movements that challenge contradictions of capitalist growth and technological development through reflexive and existential means, is especially instructive (Giddens 1991). Without community-based institutions, the more successful of which combine the skill sets of both experts and lay people, and continuously provide new types of hybrid social knowledge for people caught up in these changes, considerable suffering and clearly less progress in meeting these chal- 
lenges will prevail. Social suffering, in this sense, is caused by disorders and inversions that threaten to destroy the sociocultural fabric of the modern world, understood by Roy Rappaport as environmental degradation, population increase, warfare, globalisation, development and threats to cultural autonomy (Rappaport 1994). At the community level, these typically manifest as social pathologies, including crime, environmental and mental illnesses, family dissolution, homelessness, but also human and organ trafficking. Expert and lay groups taking collective action on behalf of sustainability and maintenance of the global commons view shifting organisational arrangements as examples of institutional bricolage, meaning a patchwork of well-worn practices adapted to new conditions; hence, there is a sense of incremental tweaking or muddling through in carrying out necessary tasks. These newer formations typically use ideas, tools and other forms of bricolage, borrowed from older institutional traditions, to craft strategies for survival and sustainability (Cleaver and de Koning 2015). The question of whether bricolage can be transformational remains unanswered, as there continues to be uneven distribution of power between the centre and the nascent, peripheral, community-based organisations forged as crisis formations and adaptations to extreme conditions, such as ecological threats to common pool resources, and the risks and hazards of modernity. To this end, the task of restoring the urban commons - an ecological, economic and equity-related challenge - involves a form of counter-hegemonic education and reflective and critical practices forwarded by Paulo Freire to promote collective action on behalf of social justice at the local level, and obtaining a clearer understanding of the relationships individual groups have to power, providing the opportunity to rearrange such relationships (Freire 1970).

Returning now to the community-based concerns of anthropologists engaged in sustainability research and practice, the operational framework of a community of practice is instructive. All communities of practice contain three structural elements: domain, or the area of shared enquiry; community, or the environment where relationships are built; and practice, or the body of knowledge, methods, tools, cases and stories put into action. A community of practice, therefore, is comprised of individuals who share a common interest in a specific domain of knowledge (Lave 1996). As a collaborative peer network based upon a shared area of inquiry, communities of practice are primarily voluntary and focused on learning and on building capacity. They are engaged in sharing knowledge, developing expertise and solving prob- lems within the specific area. Within communities of practice, local, regional, national and even global actors develop collaborative partnerships, on behalf of greater transparency in planning and implementing broad-based and inclusive sustainable practices. A community of practice is comprised of individuals who share a common concern for a specific domain of knowledge. As collaborative peer networks based upon a shared area of inquiry, communities of practice are voluntary and focused both on learning and on building capacity through collaborative relationships. They are engaged in sharing knowledge, developing expertise and solving problems. Communities of practice break down communication barriers through continuous exchange of knowledge in a more open and informal manner. In this way, they also operate as a knowledge commons, a shared socialecological system that supports the flow of communication among members of collaborative practice communities (Hess and Ostrom 2006). However, to sustain a knowledge commons, in this case on behalf of local and global sustainability, communities of practice can work towards diminishing the boundaries between the expert producers of such knowledge within the academic, public, non-profit and private sectors, and lay consumers across these sectors. Translating anthropological research into action promotes better understanding, so that both experts and the lay public may meaningfully engage in informed dialogues about their common concerns for sustainable communities (Beck and Maida 2015). Collaborative methods, such as participatory research, will insure a more socially responsive sharing of anthropological knowledge across diverse sectors and constituencies. A critical anthropological approach also orients participants towards a deeper democratic lifeway creating the opportunity for 'environmental stewardship' and 'global citizenship', even at the local level.

This special issue focuses on eight case-based articles and one theoretical article on communities of practice, within and beyond anthropological frameworks, to illustrate how participatory researchers, students, policy and community leaders, and the broader public, come to engage in community-based transformational sustainability research and practice. Authors discuss in their articles how networks of researchers, practitioners and experts communicate with a wider audience to translate sustainability concepts into terms broadly understood by the public, and on how emergent communities of practice ensure greater engagement by the public, as citizens, activists and citizen scientists, locally, regionally, nationally and globally. The authors also address the ways that class, 
gender and ethnicity play a role in how these communities meet the challenges of global sustainability. Within this framework, contributors explore communities of practice on behalf of rural and urban sustainability in Latin America, Asia, Europe and the United States. The first set of articles focus on the Global North, specifically Western Europe and North America. Krista Harper and Ana Isabel Afonso use ethnographic and Photovoice techniques to document how urban gardeners in Lisbon, Portugal cultivate the spirit of civic ecology while growing food in interstitial urban spaces. Sandy Smith-Nonini discusses lessons learned from a social enterprise project - a non-profit co-op of upcycler crafters and vintage vendors - supporting sustainability education in central North Carolina. Sam Beck looks at the movement for affordable housing in Williamsburg, Brooklyn, where Puerto Rican residents engage in a struggle against displacement, and for self-determination and community sustainability by advocating for and achieving low- and moderate-income housing in a rapidly gentrifying community. Brian McKenna provides a case of bureaucratic cooptation of a community of practice mobilised to confront local environmental health problems, specifically water and air pollution, and restaurant health, in mid-Michigan. The second set of articles, which will appear in a subsequent issue, focus on the Global South, specifically South America and South Asia.

\section{Acknowledgements}

We would like to thank the Organising Committee of the XVII World Conference of the International Union of Anthropological and Ethnological Sciences, held in Manchester, U.K. in August 2013, with the theme of Evolving Humanity, Emerging Worlds, for support of the session that would bring together the various authors in this special issue for a day of presentations, discussions and conviviality. We are grateful to Brian McKenna and Bruce Woych for their critical reading of this introduction and their suggestions for revision. We are also grateful to Marion and Vivian Berghahn, and to Christine McCourt, for their support during the entire process of putting this special issue together.

CARL A. MAIDA is a professor at the UCLA Institute of the Environment and Sustainability in the College of Letters and Science, where he teaches courses on action research methods and conducts community-based research on urban sustainability. His current research focuses on the ongoing dialogue between professional and lay knowledge in the areas of health, the quality of life and sustainability of urban communities, and on the larger national and global debates on access to public goods. He is a member of the UCLA Campus Sustainability Committee, and chairs its Academic Committee. He is a Fellow of the American Association for the Advancement of Science, the American Anthropological Association and the Society for Applied Anthropology. E-mail: cmaida@ucla.edu

SAM BECK is Senior Lecturer at Cornell University where he directs the Urban Semester Program. He has dedicated himself in the last twenty years to an activist role as an anthropologist carrying out research in North Brooklyn. As such he is an active Executive Board member in local community-based organisations that insist on being recognised with dignity and respect and struggle for community sustainability. He is a member of the Vernon Avenue Project and its spinoff Reconnect Industries, Churches United for Fair Housing, The Grand Street Boys and Brooklyn Legal Services A. He has received multiple awards for his community service work and as a teacher. E-mail: sb43@cornell.edu

\section{References}

Agrawal, A. (2003), 'Sustainable Governance of Common-pool Resources: Context, Methods, and Politics', Annual Review of Anthropology 32: 243-62. doi: 10.1146/annurev.anthro.32.061002.093112

Bäckstrand, K. (2003), ‘Civic Science for Sustainability: Reframing the Role of Experts, Policy-makers and Citizens in Environmental Governance', Global Environmental Politics 3, no. 4: 24-41.

Beck, S. and C. A. Maida (eds.) (2015), Public Anthropology in a Borderless World (New York: Berghahn).

Bonney, R., C. B. Cooper, J. Dickinson, S. Kelling, T. Phillips, K.V. Rosenberg and

J. Shirk (2009), 'Citizen Science: A Developing Tool for Expanding Science Knowledge and Scientific Literacy', BioScience 59, no. 11: 977-84.

Brossard, D., B. Lewenstein and R. Bonney (2005), 'Scientific Knowledge and Attitude Change: The Impact of a Citizen Science Project', International Journal of Science Education 27, no 9: 1099-121.

Bruffee, K. A. (1999), Collaborative Learning: Higher Education, Interdependence, and the Authority of Knowledge, 2nd ed. (Baltimore: Johns Hopkins University Press).

Cleaver, F. and J. de Koning (2015), 'Furthering Critical Institutionalism', International Journal of the Commons 9, no. 1: 1-18. 
Freire, P. (1970), Pedagogy of the Oppressed (New York: Continuum).

Gibson, H. and S. Venkateswar (2015), 'Anthropological Engagement with the Anthropocene: A Critical Review', Environment and Society: Advances in Research 6, no. 1: 5-27.

Giddens, A. (1991), Modernity and Self-identity: Self and Society in the Late Modern Age (Stanford, CA: Stanford University Press).

Heaney, C. D., S. Wilson and O. R. Wilson (2007), 'The West End Revitalization Association's Communityowned and -Managed Research Model:

Development, Implementation, and Action', Progress in Community Health Partnerships: Research Education, and Action 1, no. 4: 339-49.

Hess, C. and E. Ostrom (eds.) (2006), Understanding Knowledge as a Commons: From Theory to Practice (Cambridge, MA: MIT Press).

Lave, J. (1988), Cognition in Practice (New York: Cambridge University Press).

Lave, J. (1996), 'Teaching, as Learning, in Practice', Mind, Culture, and Activity 3, no. 3: 149-64.

Lave, J. and E. Wenger (1991), Situated Learning: Legitimate Peripheral Participation (New York: Cambridge University Press).

Maida, C. A. (ed.) (2007), Sustainability and Communities of Place (New York and Oxford: Berghahn).
Morello-Frosch, R., M. Pastor, J. Sadd, C. Porras and M. Prichard (2005), 'Citizens, Science, and Data Judo: Leveraging Community-based Participatory Research to Build a Regional Collaborative for Environmental Justice in Southern California', in Methods for Conducting Community-based Participatory Research in Public Health, (eds.) B. A. Israel, E. Eng, A. J. Schulz and E. A. Parker (San Francisco: JosseyBass), 371-91.

Morello-Frosch, R., J. G. Brody, P. Brown, R. G. Altman, R. A. Rudel and C. Pérez (2009), 'Toxic Ignorance and Right-to-know in Biomonitoring Results Communication: A Survey of Scientists and Study Participants', Environmental Health 8, no. 6. doi: 10.1186/1476-069X-8-6

Ostrom, E. (2008), 'The Challenge of Common-pool Resources', Environment: Science and Policy for Sustainable Development 50, no. 4: 8-21. doi: 10.3200/

ENVT.50.4.8-21

Rappaport, R. (1994), 'Disorders of Our Own', in Diagnosing America: Anthropology and Public Engagement, (ed.) S. Forman (Ann Arbor: The University of Michigan Press), 235-94.

Reid, H. and B. Taylor (2010), Recovering the Commons: Democracy, Place and Social Justice (Champaign, IL: University of Illinois Press).

Wenger, E. (2000), 'Communities of Practice and Social Learning Systems', Organization 7, no. 2: 225-46. 